\title{
SITIO LOMA DE LOS MUERTOS. \\ MÚLTIPLES OCUPACIONES SOBRE UN MÉDANO DEL ESTE DE NORPATAGONIA (ARGENTINA)
}

\author{
LUCIANO PRATES; VIOLETA DI PRADO"; EMILIANO MANGE ${ }^{* * *}$ Y ALEJANDRO SERNA"
}

\begin{abstract}
RESUMEN
En este trabajo se presentan los resultados del estudio del contexto arqueológico del sitio Loma de los Muertos (departamento de General Conesa, provincia de Río Negro, Argentina). En el sitio se llevaron a cabo actividades múltiples asociadas a un campamento residencial y se realizaron entierros humanos y de, al menos, un cánido extinto (Dusicyon avus). Se obtuvieron tres fechados para los entierros humanos y uno para los restos del carnívoro, que los ubican entre ca. 3.000 y 2.000 años AP. Complementariamente, los materiales de superficie asociados al campamento fueron fechados en ca. 500 años AP. Sobre la base de esta información, fueron inferidos al menos cuatro episodios diferentes de ocupación. La mayor parte de las materias primas líticas utilizadas y reducidas en el sitio se obtuvieron de fuentes locales de aprovisionamiento. Con ellas se fabricaron instrumentos de filo (principalmente raspadores) y de superficies activas (sobre todo de molienda). Se explotaron varias clases de fauna, como mamíferos (guanaco y venado de las pampas); aves (ñandú); peces y moluscos de agua dulce; todos disponibles en proximidades del sitio. El estudio de los restos de alfarería permitió reconstruir el perfil de un recipiente que fue utilizado posiblemente para el procesamiento de alimentos sobre el fuego. Las evidencias disponibles no prueban la contemporaneidad de los entierros y las actividades de campamento.
\end{abstract}

PALABRAS CLAVES: Norpatagonia, Holoceno tardío, médano, campamento base, entierros humanos.

* CONICET, Museo de La Plata, Universidad Nacional de La Plata. Paseo del Bosque s/n (1900), La Plata, Argentina. lprates@ fcnym.unlp.edu.ar, violetadiprado@hotmail.com

* Facultad de Ciencias Naturales y Museo, Universidad Nacional de La Plata. Paseo del Bosque s/n (1900), La Plata, Argentina. emilianomange@gmail.com, aleserna@hotmail.com 


\title{
LOMA DE LOS MUERTOS SITE. MULTIPLE OCCUPATIONS ON A SAND DUNE IN EAST NORPATAGONIA (ARGENTINA)
}

\begin{abstract}
In this article the results of the analysis of the archaeological record of Loma de los Muertos site (General Conesa district, Río Negro province, Argentine) is presented. In this site, domestic and two inhumatory activities were carried out, including human burials and, at least, one extint carnivore (Dusicyon avus). Three radiocarbon dates were obtained from the human burials and one for the canid remains, which locate the site in a time span between ca. 3.000 and 2.000 years BP. As a complement, the surface domestic materials related to the camp site were dated in ca. 500 years BP. Materials for lithic artefacts were obtained from both primary (sandstone for ground stone tools) and secondary sources (volcanic cobbles for knapped tools). Archaeofauna remain analysis shows several animals were exploited, such as mammals (guanaco and pampean deer), birds (ñandú -sudamerican ostrich-), fishes and freshwater molluscs, all available nearby the site. Pottery remains studies allowed reconstructing a complete vessel which was probably used in a domestic context. There are no evidences to prove chronological association between inhumatory and domestic activities at the site.
\end{abstract}

KEYWORDS: Norpatagonia, late Holocene, sand dune, campsite, human burials.

\section{INTRODUCCIÓN}

El sector este de Norpatagonia se caracteriza por una densidad inusual de sitios arqueológicos con entierros humanos, sobre todo a lo largo del litoral marítimo y de los sectores inferiores de las cuencas de los ríos Colorado y Negro (entre otros Moreno 1874; Fisher y Nacuzzi 1992; Sanguinetti de Bórmida 1999; Martínez et al. 2006; Prates et al. 2006; Borella et al. 2007; véase síntesis en Prates 2008). Muchos de estos sitios se encuentran asociados con geoformas eólicas (médanos) y, en la mayoría de los casos, los mismos espacios fueron utilizados no sólo para efectuar prácticas mortuorias, sino también como áreas de campamento residenciales. Hasta hace poco tiempo, los estudios efectuados en sitios similares se centraron en el análisis de los restos humanos, siendo escasamente considerados otros tipos de evidencias arqueológicas (por ej. Moreno 1874; Lehmann-Nitsche 1930; Vignati 1938).

En este trabajo se dan a conocer los resultados de las investigaciones efectuadas en el sitio Loma de los Muertos (en adelante LM), ubicado en la margen sur del valle del río Negro, departamento de General Conesa, provincia de Río Negro $\left(40^{\circ}\right.$ 08' 47,03" S y 64 16' 19,54" O) (Figura 1). Este sitio fue hallado accidentalmente en un médano fijo cuando se interceptaron y expusieron parcialmente varios esqueletos humanos mientras se efectuaban actividades de remoción de tierra con una pala mecánica. El médano en que se hallaron los materiales tiene una superficie aproximada de $25.300 \mathrm{~m}^{2}$ (ca. $220 \times 115 \mathrm{~m}$ ) y se encuentra a pocos metros al oeste de una laguna en collera ${ }^{1}$, a $1,4 \mathrm{~km}$ al sudoeste del cauce actual del río y a $4 \mathrm{~km}$ al noreste de las mesetas ubicadas al sur de la cuenca.

Durante los primeros trabajos sistemáticos efectuados en LM en 2007, se constató la presencia de diversos tipos de evidencias arqueológicas. Se registraron cuatro entierros (de los cuales se excavaron tres) y abundantes restos óseos humanos; artefactos líticos tallados (núcleos, instrumentos y desechos de talla); artefactos líticos manufacturados por picado, abrasión y pulido, y modificados por uso (instrumentos de molienda, percutores, sobadores y bolas de boleadora); restos faunísticos (restos óseos, dientes, valvas de moluscos marinos y fluviales, y cáscaras de huevo de rheidos); restos de cerámica (fragmentos de

1 Este tipo de laguna es muy común en todo el valle del río y se forma en los codos de los meandros de los paleocauces de la planicie aluvial moderna (Luchsinger 2006). El lecho de las lagunas se forma por el socavamiento ejercido por el agua durante las inundaciones de magnitud. En la misma planicie aluvial, pero en el sector norte, fueron identificados varios paleocauces, todos ellos formados durante el Holoceno tardío, entre 2.500 y 200 años AP (Luchsinger 2006; Luchsinger y Prates 2009). 


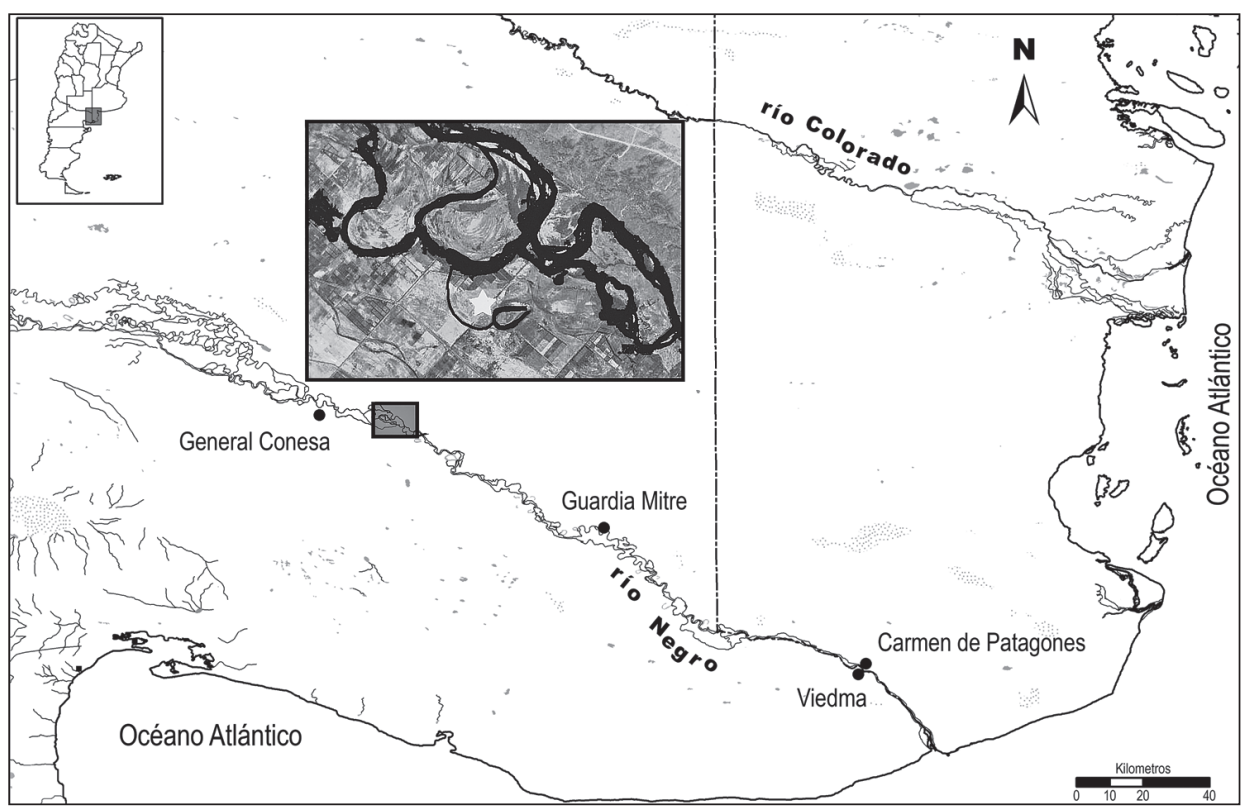

Fig. 1. Ubicación del sitio Loma de los Muertos.

borde y cuerpo); dos pigmentos minerales (uno rojo y otro amarillo) y elementos ornamentales perforados elaborados sobre valva $(n=2)$ y sobre hueso $(n=1)$. Los únicos materiales identificados en estratigrafía fueron los restos óseos humanos de cinco individuos, que serán descriptos sucintamente debido a que fueron tratados en profundidad en una publicación previa (Prates et al. 2010a, en este volumen), y dos esqueletos semi-completos de cánido. El registro de abundantes materiales óseos humanos dispersos en la superficie del médano permite inferir que quedan entierros no detectados. El objetivo de este trabajo es presentar los resultados del análisis integral de los distintos materiales y generar hipótesis sobre los procesos naturales y culturales de formación de este sitio.

\section{MATERIALES Y MÉTODOS}

La primera tarea realizada en el sitio fue el relevamiento de la superficie del médano y la delimitación del área de dispersión de restos arqueológicos. Luego se efectuaron levantamientos planimétricos y muestreos sistemáticos de materiales superficiales. Para los muestreos se delimitaron cuatro áreas de un metro cuadrado, en las que se recolectó la totalidad de hallazgos. Para determinar la dispersión vertical de los restos de superficie, identificar la presencia de materiales en posición estratigráfica y localizar nuevas áreas de entierro, se efectuaron cuatro trincheras $(0,5 \times 5 \mathrm{~m})$ y dos pozos de sondeo $(0,5$ x $0,5 \mathrm{~m}$ ) (Figura 2).

El análisis de los materiales líticos se llevó a cabo siguiendo los lineamientos de Aschero (1983), Aschero y Hocsman (2004) y Babot (2004). Teniendo en cuenta las limitaciones para la determinación macroscópica de algunos tipos de roca, las materias primas fueron agrupadas en categorías generales (véase Tabla 1). La fauna fue determinada utilizando colecciones óseas de comparación del Museo de La Plata y aplicando las metodologías de varios autores (Behrensmeyer 1978; Lyman 1994; Miotti 1998; entre otros). La descripción, caracterización e interpretación del conjunto cerámico se llevó a cabo siguiendo los lineamientos generales de Rice (1987), Balfet et al. (1992), Skibo (1992) y Orton et al. (1997).

\section{RESULTADOS}

\section{Descripción general del contexto mortuorio}

En LM fueron excavados tres entierros humanos; todos ellos expuestos parcialmente durante los trabajos de nivelación efectuados en el lugar. Como fue señalado, sólo haremos una descripción de sus 


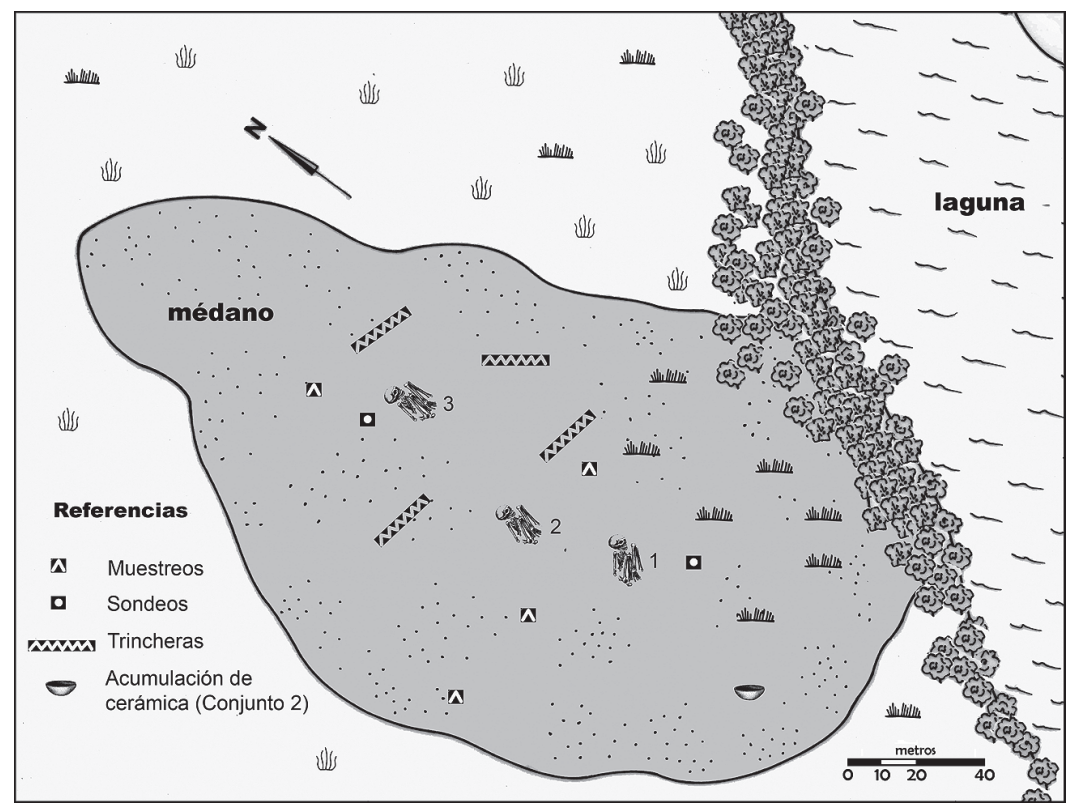

Fig. 2. Plano del sitio Loma de los Muertos.

características principales (para mayores detalles véase Prates et al. 2010a, en este volumen). El entierro 1 está integrado por un número mínimo de tres individuos. El principal corresponde a una inhumación primaria simple, con una cronología de $2.088 \pm 46$ años ${ }^{14} \mathrm{C} \mathrm{AP}$; el cráneo no presenta alteraciones óseas y se identificó la presencia de deformación artificial de tipo tabular oblicua. El entierro 2 corresponde a una inhumación primaria con una cronología de $3.027 \pm 48$ años ${ }^{14} \mathrm{CAP}$; el cráneo no muestra evidencias de deformación artificial y se observó una caries en la mandíbula. El entierro 3 es una inhumación primaria con una cronología de $2.718 \pm 47$ años ${ }^{14} \mathrm{CAP}$; no se reconocieron signos de deformación artificial en el cráneo y se registraron tres caries.

Uno de los aspectos más destacables de LM es el hallazgo de dos esqueletos de cánidos semi-completos a ca. dos metros de la ubicación original del entierro 3 (Figura 3). Muchos huesos se encontraban dispersos en la matriz sedimentaria debido a que, como los huesos humanos, fueron afectados por las tareas de remoción del médano. El estado de preservación de estos materiales es muy bueno y no presentan meteorización ni marcas de procesamiento. Algunos elementos correspondientes al esqueleto más completo se encontraban en posición anatómica al momento del hallazgo.
Este último esqueleto fue asignado a Dusicyon avus y está conformado por la caja craneana con las bulas timpánicas, los cóndilos occipitales, las cavidades glenoideas y los frontales. El rostro está fragmentado y se conservan los maxilares aislados con parte de la dentición (P4-M2 derechos, P1-2 izquierdos). La mandíbula izquierda posee un buen estado de preservación y porta los c1, p2-m2. Del post-cráneo se conservan el húmero, radio, cúbito (articulados), fémur y cuarto metatarsiano derechos. Varias de las epífisis de estos huesos largos no estaban fusionadas, por lo que no se preservaron. La dentición muestra escaso desgaste en sus cúspides. La sutura basioccipitalbasiesfenoides, aunque puede observarse todavía, está casi obliterada. Esto, sumado a la ausencia de fusión de algunas epífisis de los huesos largos, indica que el ejemplar era un sub-adulto, de aproximadamente un año. De este individuo se obtuvo un fechado taxón de $2.972 \pm 50$ años ${ }^{14} \mathrm{C}$ años AP (AMS, AA83516).

Del segundo individuo se recuperaron una porción del cráneo, ambos fémures y parte de la escápula izquierda. Las epífisis distales de los fémures no se encuentran fusionadas, lo que muestra que se trata de un individuo sub-adulto. Se está avanzando en la asignación taxonómica de estos restos, que corresponderían a $D$. avus o D. culpaeus. 


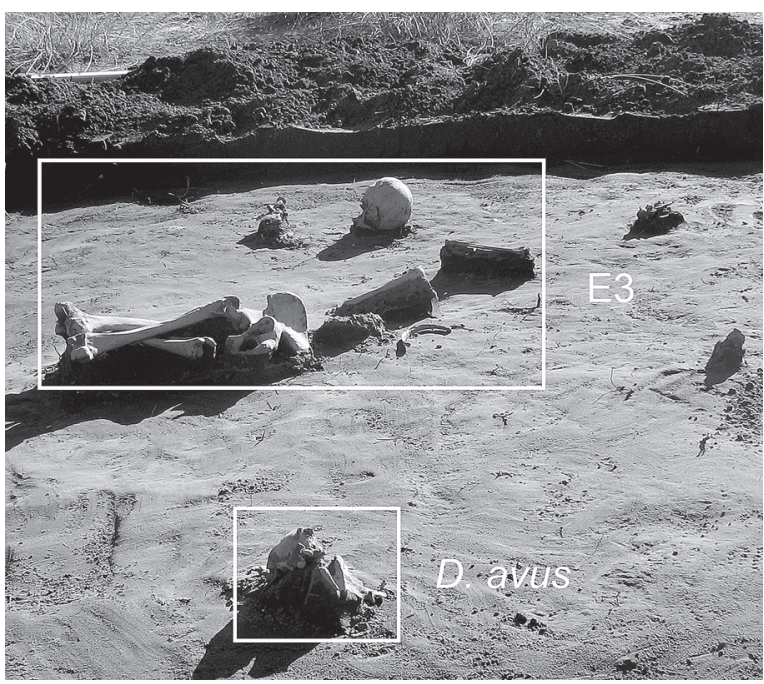

Fig. 3. Entierro 3 y entierro de Dusicyon avus.

\section{Análisis de los artefactos líticos}

El conjunto lítico de LM está constituido por un total de 201 artefactos: desechos de talla ( $n=128)$, instrumentos $(n=68)$ y núcleos $(n=5)$ de diversas materias primas. Entre las rocas con fractura concóidea predominan las silíceas y las ígneas (Tabla 1) y, en su mayoría, fueron obtenidas de rodados. En las rocas sin fractura concóidea son mayoritarias las areniscas de color gris, obtenidas principalmente de la formación Río Negro, que constituye la roca de base del valle del río homónimo (Andreis 1965). En pocos casos se determinaron materias primas de carácter no local: una cuarcita blanca de grano fino $(n=1)$ y una de tonalidades rosadas de grano mediano $(n=2)$.

Entre los desechos de talla predominan las lascas (68\%; $\mathrm{n}=87$ ), seguidas por los indiferenciados $(21,9 \% ; n=28)$ y los no clasificables $(10,2 \% ; n=13)$. Los núcleos son de rocas obtenidas de rodados (tres de ígneas de grano fino y dos de silíceas) y están representados por los siguientes tipos morfológicos: de lascados aislados $(n=2)$, lascas nodulares $(n=2)$ y bifaciales irregulares $(n=1)$. Todos fueron descartados, aun cuando el volumen de roca disponible en ellos era abundante, y se extrajeron muy pocas lascas a cada uno (2,4 en promedio).

El conjunto de instrumentos $(n=68)$ está constituido por 28 artefactos de filo manufacturados por talla (Figura 4) y 40 artefactos no tallados (modificados por picado, abrasión y/o pulido y modificados por uso, Figura 5). Los primeros fueron confeccionados principalmente sobre rocas silíceas $(64,3 \% ; n=18)$ y sobre rocas ígneas de grano fino $(21,4 \% ; n=6)$. La mayoría corresponde a la clase técnica de los unifaciales marginales (75\%; $\mathrm{n}=21)$, seguidos por los de adelgazamiento bifacial (21,4\%; $\mathrm{n}=6)$ y los alternos marginales $(3,6 \% ; n=1)$. Los grupos tipológicos más representados son los raspadores (42,9\%; $n=12$, figura $4 a-h)$, los artefactos de formatización sumaria $(21,4 \% ; n=6)$ y las puntas de proyectil $(17,9 \% ; n=5)$; los restantes grupos tipológicos están representados por un artefacto cada uno (cepillos, cuchillos, muescas, raederas e instrumentos compuestos). Un aspecto destacable de los instrumentos tallados es la diversidad morfológica de las puntas de proyectil, que incluye una preforma, una triangular mediana apedunculada, una triangular pequeña apedunculada, una triangular mediana con pedúnculo y una preforma triangular pequeña apedunculada (Figura 4i-n).

En el caso de los instrumentos no tallados, la materia prima más utilizada fue la arenisca gris de la formación Río Negro (55\%; n=22), seguida por las ígneas de grano medio $(17,5 \% ; n=7)$ y las ígneas de grano grueso $(15 \% ; n=6)$. Las metamórficas (5\%; $\mathrm{n}=2)$, las indeterminadas $(5 \% ; \mathrm{n}=2)$ y las ígneas de grano fino $(2,5 \% ; n=1)$ están menos representadas. En cuanto a las categorías morfo-funcionales, se encuentran representados los instrumentos de molienda $(n=24)$, los instrumentos compuestos $(n=4)$, las armas -todas bolas de boleadora- $(n=8)$ y los instrumentos no diferenciados $(n=4)$. Entre los instrumentos de molienda predominan los no diferenciados $(n=13)$; les siguen en frecuencias más bajas los activos indefinidos $(n=4)$, pasivos indefinidos $(n=2)$, mor-

Tabla 1. Materias primas líticas representadas en LM.

\begin{tabular}{|c|c|c|c|c|c|c|c|}
\hline & Ígneas grano fino* & Ígneas grano medio & Ígneas grano grueso & Silíceas $^{* *}$ & Arenisca & Otras & Total \\
\hline $\mathrm{n}$ & 48 & 28 & 8 & 94 & 23 & 6 & 207 \\
\hline$\%$ & 23,2 & 13,5 & 3,9 & 45,4 & 11,1 & 2,9 & 100 \\
\hline
\end{tabular}

* En esta categoría todas las rocas se definieron como basaltos.

"En esta categoría se incluyen las sílices, las calcedonias y los cuarzos; estos últimos muy escasos. 


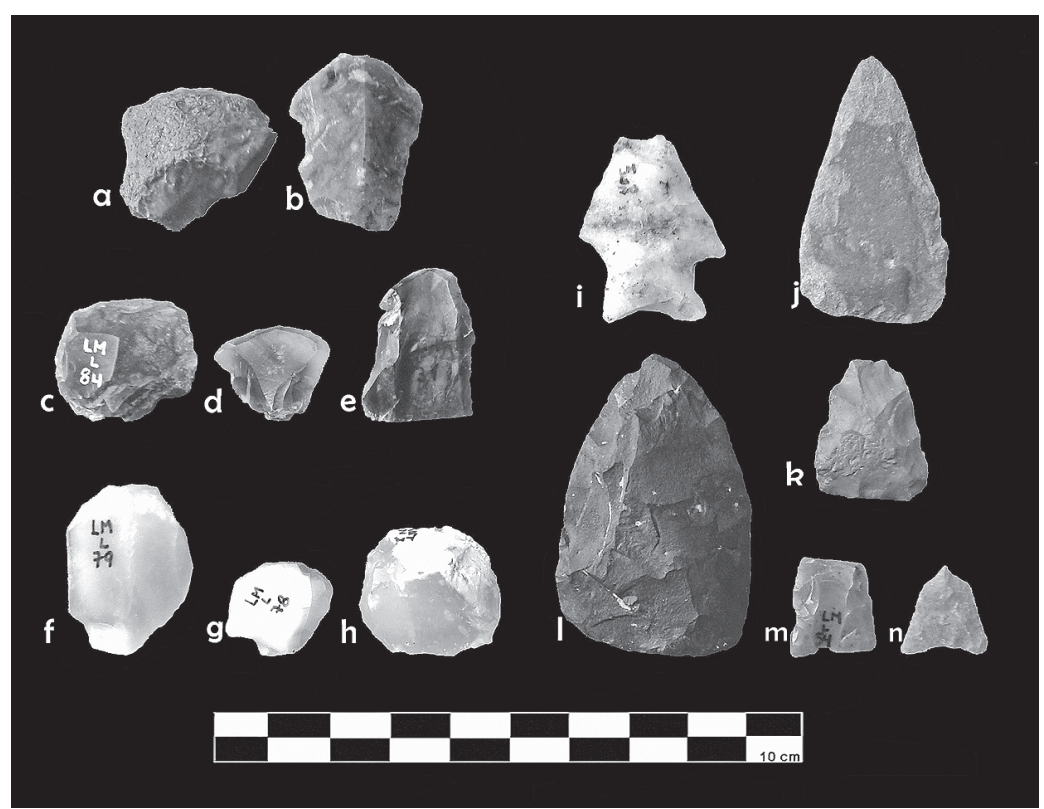

Fig. 4. Instrumentos de filo manufacturados por talla.

teros $(n=2)$, molinos $(n=2)$ y sobadores $(n=1)$. Entre los instrumentos compuestos se registraron tres sobador-percutor y un sobador-percutor-yunque. Las bolas de boleadora son todas lisas, de tamaño muy variable (entre 3,4 y 7,1 cm de diámetro) y ninguna presenta surco perimetral (Figura 5a-h). Cuatro se encuentran completas, tres están fracturadas y una fue descartada antes de finalizada la manufactura (Figura 5a).

\section{Análisis de los restos faunísticos}

La muestra de fauna analizada está constituida por un NISP=749; el 60,6\% se obtuvo de las cuadrículas de muestreo y de los sondeos estratigráficos y el 39,4\% restante de recolecciones superficiales selectivas (Tabla 2). El 74,6\% $(n=559)$ son restos óseos, el 17,2\% ( $n=129)$ valvas de moluscos y el $8,1 \%$ ( $\mathrm{n}=61$ ) fragmentos de cáscara de huevo de Rheidae. A partir de un metapodio de Lama guanicoe se obtuvo una edad radiocarbónica convencional de 520 \pm 90 años AP (LP-2005).

El estado de meteorización exhibido por los especímenes óseos es bajo. Según los criterios propuestos por Behrensmeyer (1978), el 71\% presenta estadio de meteorización 1 , el $4,2 \%$ se encuentra entre los estadios 1 y 2 , el $16,9 \%$ presenta estadio 2 y el $1,4 \%$ se encuentra entre los estadios 2 y 3.

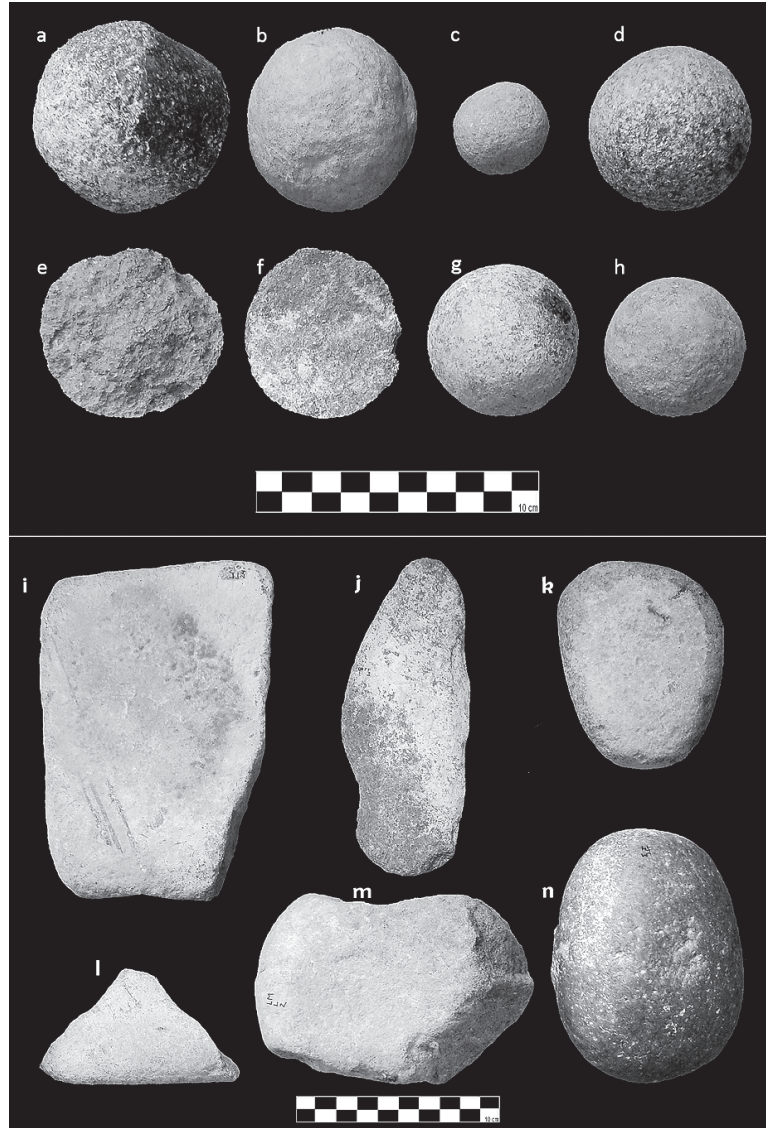

Fig. 5. Instrumentos no tallados. 
Tabla 2. Lista taxonómica de los restos faunísticos de LM.

\begin{tabular}{|c|c|c|c|c|}
\hline & TAXA & Superficie & Muestreos y sondeos & Total \\
\hline \multirow{14}{*}{ 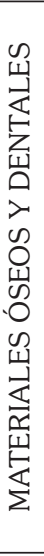 } & Indeterminado & 17 & 164 & 181 \\
\hline & Mammalia indet. & 19 & 4 & 23 \\
\hline & Artiodactila indet. & 6 & 0 & 6 \\
\hline & Lama guanicoe & 37 & 0 & 37 \\
\hline & Ozotoceros bezoarticus & 11 & 2 & 13 \\
\hline & Dusicyon sp. & 19 & 0 & 19 \\
\hline & Dasypodidae (placas dérmicas) ${ }^{(1)}$ & 99 & 21 & 120 \\
\hline & Chaetophractus villosus (huesos) & 2 & 0 & 2 \\
\hline & Rodentia indet. & 2 & 24 & 26 \\
\hline & Holochilus brasiliensis & 2 & 0 & 2 \\
\hline & Ctenomydae indet. & 1 & 5 & 6 \\
\hline & Ave indet. & 1 & 5 & 6 \\
\hline & Rhea americana & 10 & 0 & 10 \\
\hline & Osteichtyes indet. & 24 & 84 & 108 \\
\hline \multirow{5}{*}{$\begin{array}{l}\stackrel{\infty}{0} \\
\stackrel{1}{5} \\
0\end{array}$} & Diplodon chilensis & 6 & 66 & 72 \\
\hline & Chilina sp. & 8 & 29 & 37 \\
\hline & Rheidae (cáscara de huevo) ${ }^{(2)}$ & 12 & 49 & 61 \\
\hline & Volutidae indet. (marinos) & 19 & 1 & 20 \\
\hline & Total & 295 & 454 & 749 \\
\hline
\end{tabular}

(1) Aunque no se cuantificaron, se determinó la presencia de Chaetophractus villosus y Zaedyus pichiy. ${ }^{(2)}$ En un trabajo previo (Apolinaire y Turnes 2008) se determinó la presencia de cáscaras de huevo de Rhea americana y Pterocnemia pennata.

Se registraron marcas de raíces en el $19,9 \%$ de los especímenes, fracturas en seco en el 38,3\%, marcas de roedores en el 8,9\% y de carnívoros en el 0,68\%. La muestra está conformada por mamíferos grandes (guanaco), medianos (zorros y venado de las pampas) y pequeños (peludo, rata nutria y tuco-tuco); aves (ambas especies de ñandú); peces y moluscos fluviales y marinos (indet.) (Tabla 2).

En el caso del guanaco, se calculó un $\mathrm{NMI}=2$ a partir de la representación de radiocúbitos, pelvis y metapodios. En esta especie se registraron varias evidencias seguras de explotación antrópica (Tabla 3), como marcas de corte sobre una epífisis de radiocúbito y sobre una diáfisis de metapodio y marcas de impacto (puntos de impacto y negativos de lascado) en un fémur y en un metatarso. También se identificaron algunas posibles evidencias de acción antrópica, como marcas de combustión (en un radiocúbito, en un húmero y en un calcáneo) y fracturas en estado fresco en el 36,1\% de los restos. De acuerdo con el MAU\% (Figura 6), si bien se encuentran más representados los elementos del esqueleto apendicular, la presencia de algunas partes del esqueleto axial, como hemimandíbulas y una vértebra, sugiere que al menos uno de los guanacos pudo ser ingresado entero al sitio.
Para el venado de las pampas también se calculó un $\mathrm{NMI}=2$, a partir de la representación de escápulas. La explotación antrópica fue inferida a partir de la presencia de marcas de machacado en una hemimandíbula y de corte y posible perforación en la base de un asta (Tabla 3). Al mismo tiempo,

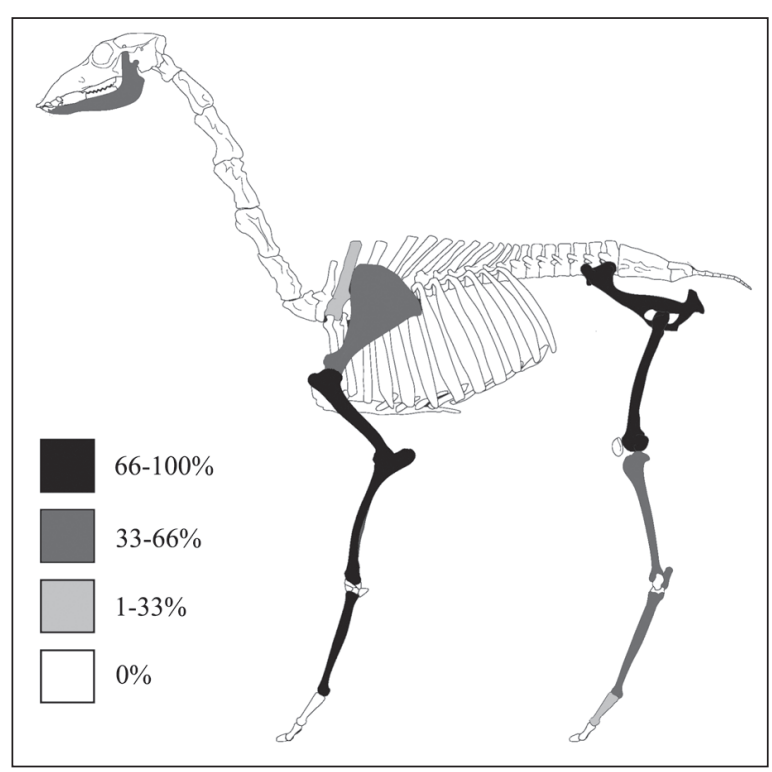

Fig. 6. MAU \% de las partes esqueletarias de guanaco. 
Tabla 3. Alteraciones y marcas registradas en los restos faunísticos.

\begin{tabular}{|c|c|c|c|c|c|c|}
\hline & TAXA & $\begin{array}{c}\text { Alteraciones } \\
\text { térmicas }\end{array}$ & Marcas de corte & $\begin{array}{l}\text { Fracturas } \\
\text { frescas }\end{array}$ & $\begin{array}{l}\text { Marcas de } \\
\text { impacto }\end{array}$ & Total $^{(1)}$ \\
\hline \multirow{13}{*}{ 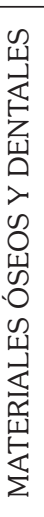 } & Indeterminado & 45 & 2 & 3 & 0 & 49 \\
\hline & Mammalia indet. & 1 & 1 & 1 & 1 & 3 \\
\hline & Artiodactila indet. & 0 & 0 & 1 & 0 & 1 \\
\hline & Lama guanicoe & 3 & 2 & 13 & 3 & 18 \\
\hline & Ozotoceros bezoarticus & 1 & 1 & 3 & 1 & 6 \\
\hline & Dasypodidae (placas dérmicas) & 14 & 0 & 0 & 0 & 14 \\
\hline & Chaetophractus villosus (huesos) & 0 & 0 & 0 & 0 & 0 \\
\hline & Rodentia indet. & 2 & 0 & 0 & 0 & 2 \\
\hline & Holochilus brasiliensis & 0 & 0 & 0 & 0 & 0 \\
\hline & Ctenomydae indet. & 0 & 0 & 0 & 0 & 0 \\
\hline & Ave indet. & 0 & 0 & 0 & 0 & 0 \\
\hline & Rhea americana & 2 & 0 & 4 & 0 & 6 \\
\hline & Osteichtyes indet. & 34 & 0 & 0 & 0 & 34 \\
\hline \multirow{5}{*}{ 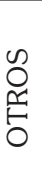 } & Diplodon chilensis & 16 & 0 & 0 & 0 & 16 \\
\hline & Chilina sp. & 0 & 0 & 0 & 0 & 0 \\
\hline & Cáscara de huevo (ñandú) & 12 & 0 & 0 & 0 & 12 \\
\hline & Volutidae indet. & 0 & 0 & 0 & 0 & 0 \\
\hline & Total & 130 & 8 & 25 & 5 & 162 \\
\hline
\end{tabular}

(1) En el total se indica el número de especímenes (no se repiten si tienen más de un tipo de evidencia).

se registraron evidencias de combustión en un fémur y fracturas óseas en estado fresco en el $23,1 \%$ de los especímenes. Si bien los restos de venado son escasos $(n=13)$, la presencia de elementos del esqueleto axial y apendicular sugiere el ingreso de animales enteros en el sitio.

El resto de los taxa posiblemente explotados en LM son el ñandú, con evidencias de combustión y fracturas óseas en estado fresco, y los peces, los dasipódidos (placas dérmicas del caparazón), los micromamíferos no determinados y los moluscos de agua dulce ( $D$. chilensis), con evidencias de combustión (Tabla 3). En el resto de los taxones representados (H. brasiliensis y Ctenomys sp.) no se registraron indicadores de aprovechamiento.

\section{Análisis de los materiales cerámicos}

En LM se recuperó un total de 400 fragmentos de cerámica con un largo máximo igual o mayor que $15 \mathrm{~mm}$; los tiestos de dimensiones menores $(\mathrm{n}=27)$ no fueron incluidos en el análisis. De este total, el $63 \%$ ( $n=252)$ son fragmentos correspondientes a los sectores de borde y cuerpo hallados dispersos en la superficie del sitio (de aquí en adelante Conjunto 1), y el $37 \%$ restante $(n=148)$ son tiestos pertenecientes al borde y cuerpo de la misma vasija (Conjunto 2 ), que fueron hallados juntos en un radio de $1 \mathrm{~m}^{2}$. Ambos conjuntos se describen e interpretan por separado, sobre todo porque la información provista por cada uno es diferente.

\section{Reconstrucción de formas}

Aunque el conjunto cerámico de LM está constituido enteramente por fragmentos, fue posible conocer la morfología y dimensiones aproximadas de algunos contenedores. En el Conjunto 1 pudieron ensamblarse pocos tiestos (cinco remontajes de dos a cuatro fragmentos, en su mayoría bordes, Figura $7 a, b, f, i) y$, en un caso, se pudo estimar el diámetro de boca de un recipiente en $180 \mathrm{~mm}$ (sensu Rice 1987:222) (Figura 7a). En el Conjunto 2 se efectuó el ensamblaje de 45 tiestos, lo que representa casi el $40 \%$ de la pieza y el $70 \%$ de la boca, aproximadamente. Los 103 fragmentos restantes no pudieron remontarse debido a su pequeño tamaño o a la ausencia de decoración, aunque fueron adjudicados a la misma vasija siguiendo el criterio de familia de fragmentos (sensu Orton et al. 1997:195). El contenedor parcialmente reconstruido fue clasificado como un cuenco grande con un diámetro de boca de $320 \mathrm{~mm}$, una altura aproximada de $135 \mathrm{~mm}$ y sin asas ni perforaciones de suspensión (Figura 7j). 


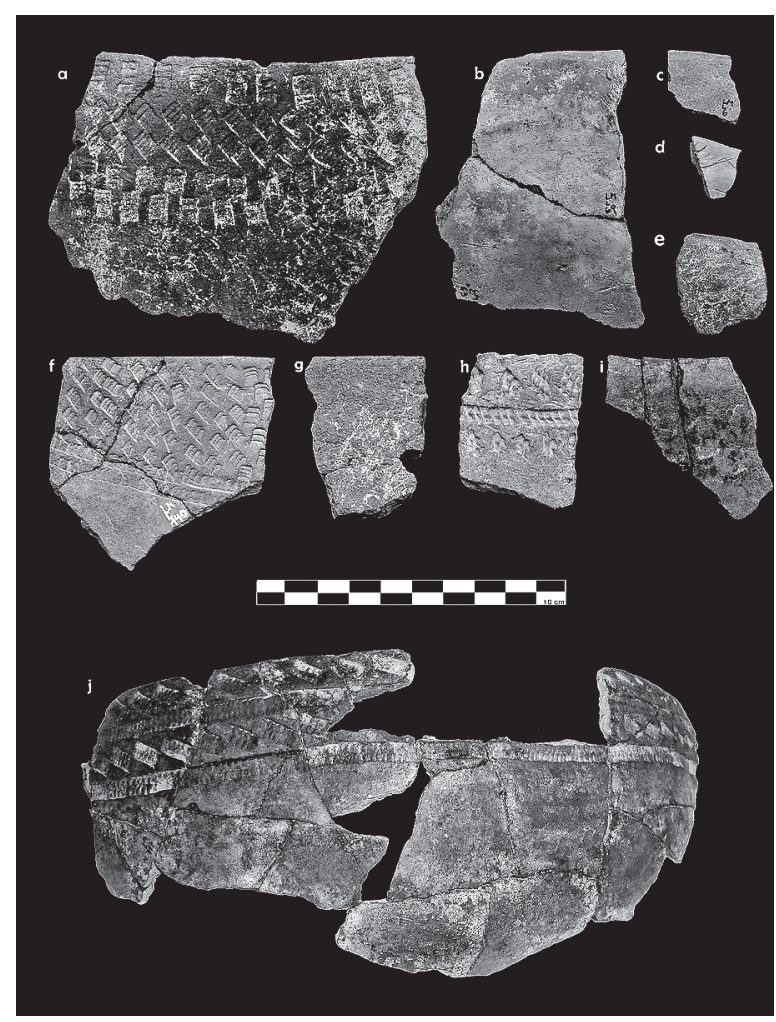

Fig. 7. Restos de alfarería recuperados en LM.

Atributos macroscópicos

El Conjunto 1 está integrado por un 90,5\% $(n=228)$ de fragmentos de cuerpo y un 9,5\% $(n=24)$ de bordes; entre estos últimos, 15 son rectos, 7 evertidos y 2 invertidos. En relación con las técnicas de tratamiento de superficie, la cara externa de los fragmentos está principalmente alisada $(63,1 \%$; $\mathrm{n}=159)$, pulida $(24,6 \% ; \mathrm{n}=62)$, poco alisada $(11,5$; $\mathrm{n}=29)$ e irregular $(0,8 \% ; \mathrm{n}=2)$. Se identificaron superficies externas con incisiones $(7,5 \% ; n=19)$, impresiones $(6,7 \% ; n=17)$ y engobe $(6,7 \% ; n=17)$, todas ellas también fueron alisadas $y / 0$ pulidas. Las superficies internas están alisadas $(64,7 \% ; n=163)$, pulidas $(26,6 ; n=67)$, poco alisadas $(4,4 \% ; n=11)$ y engobadas $(4,4 \% ; n=11)$. Las técnicas de incisión e impresión fueron identificadas en las superficies externas de 30 tiestos. La primera fue utilizada para realizar líneas rectas, zigzags, triángulos, reticulados o enrejados (formando cuadrados y rectángulos) y rayas rítmicas verticales, y la segunda para efectuar impresiones dispuestas de forma oblicua, vertical y horizontal, formando guardas. La técnica de ma- nufactura por enrollamiento o rodete se identificó en el $8,7 \%$ de los fragmentos $(n=22)$, a partir de la presencia de surcos o costuras en las uniones de los rollos (Balfet et al. 1992).

El cuenco parcialmente reconstruido (Conjunto 2) posee borde recto, labio redondeado irregular $y$, posiblemente, base cóncava. La superficie externa está alisada, con decoración zonal que se extiende $45 \mathrm{~mm}$ desde el borde hasta el cuerpo medio y que consiste en la alternancia de guardas formadas por impresiones rectangulares dispuestas en forma oblicua y horizontal; aparecen representadas cuatro guardas en total. La cara externa presenta pintura roja distribuida de forma discontinua a lo largo de toda la superficie. La superficie interna está poco alisada. Los espesores varían de acuerdo al sector de la vasija que se considere: $4-5 \mathrm{~mm}$ en el borde, $6 \mathrm{~mm}$ en el cuerpo y $7 \mathrm{~mm}$ en la base (Figura $7 \mathrm{j}$ ). El resto de los tiestos del Conjunto 2 presenta características similares, con diferencias relacionadas con el sector del cuerpo al que correspondan (diferentes espesores, presencia o ausencia de decoración y de alteraciones por uso, entre otros). A partir de la observación de la forma y dirección de las fracturas (horizontales y paralelas a la dirección de los rollos), y las líneas de unión entre rodetes, se determinó que la técnica de manufactura del cuenco, al menos en el sector del borde y el cuerpo, fue la de superposición de rollos. La observación del color de las superficies y la pasta en corte transversal, y el cotejamiento con el perfil del cuenco permitieron hacer inferencias acerca de las características del proceso de cocción (García Rosselló y Calvo Trias 2006; López 1999/2001). La pasta en el sector del borde es gris y marrón oscuro; en el sector del cuerpo se dan dos variantes: por un lado, margen interno gris claro, núcleo y margen externo gris oscuro y, por el otro, las mismas características pero con el margen externo marrón rojizo.

Por último, con el fin de calcular el número de recipientes que están representados en el sitio, se utilizó el concepto de equivalente de vasija estimado -eve- (sensu Orton et al. 1997:195). Para esto se consideraron los fragmentos de bordes (lisos y decorados) como una fracción que representa a toda la vasija (Figura 7). El eve resultante fue de 20 vasijas (se incluye el cuenco parcialmente reconstruido), que puede considerarse como el número mínimo de contenedores (NMC en Paleo y Pérez Meroni 2005/2006). 
Alteraciones por uso

Con el fin de elaborar hipótesis acerca del "uso inferido" del material cerámico, se consideraron distintos aspectos relacionados con la forma, las alteraciones por uso, las características tecnológicas, entre otras (Skibo 1992). Dentro del Conjunto 1 de tiestos, se observaron restos de hollín y ennegrecimiento en las superficies externas de 10 fragmentos de cuerpo y uno de borde $(4,4 \%)$. En las caras internas se observaron adherencias en 18 tiestos $(7,1 \%)$, posiblemente restos del contenido original de la vasija. En el caso del Conjunto 2, las evidencias directas de uso consisten en rayas paralelas y semicirculares en la superficie interna de la porción reensamblada del cuerpo inferior del cuenco. También se identificaron restos de hollín y ennegrecimiento en la superficie externa, dispuestos en forma regular principalmente a partir del cuerpo superior hasta el borde.

\section{DISCUSIÓN}

\section{Procesos de formación del sitio y cronología}

En cuanto a los procesos de formación del sitio, el principal agente que afectó la integridad del conjunto fue la intervención humana reciente vinculada con las actividades agropecuarias. La alta fragmentación y amplia dispersión espacial de los restos humanos puede ser atribuida principalmente a dichas tareas. Aun cuando los contextos de médanos se encuentran generalmente expuestos a una alta dinámica (Waters 1992; Dincauze 2000; Torben 2002), no se registraron indicadores de una participación relevante de otros agentes post-depositacionales, como marcas de roedores, carnívoros o raíces, ni signos de la acción del viento o del agua, como pátinas, abrasión o rodamiento. Tampoco se identificaron en los fragmentos óseos -incluyendo humanos y no humanos- signos importantes de meteorización, presentando la mayoría de ellos rasgos asignables al estadio 1 (sensu Behrensmeyer 1978). Asimismo, no se detectaron pátinas en el registro lítico ni evidencias marcadas de erosión en la alfarería. Esto implica que el conjunto artefactual no estuvo expuesto a las condiciones atmosféricas un tiempo lo suficientemente prolongado como para generar alteraciones significativas. Es probable que los materiales se hayan incorporado al contexto estratigráfico poco tiempo después de su abandono y hayan quedado expuestos poco antes de la recolección, luego de la remoción de parte de la cobertura vegetal del médano. Es posible, incluso, que antes de este último evento los materiales arqueológicos (artefactos líticos, faunísticos y cerámicos) hayan estado localizados muy cerca de la superficie del terreno. Esto se infiere a partir de la dispersión vertical observada en los sondeos estratigráficos y trincheras, caracterizada por la concentración del $80 \%$ de los materiales en los primeros $10 \mathrm{~cm}$ del perfil, la cual disminuye progresivamente hasta hacerse muy baja a los $35 \mathrm{~cm}$ de profundidad.

\section{El contexto mortuorio}

En relación con los entierros humanos, sólo se registraron evidencias de deformación craneana (de tipo tabular oblicua) en el individuo 1 y su cronología coincide con la esperada para este tipo de deformación (Bernal et al. 2008). No se reconocieron paleopatologías ni alteraciones no patológicas severas y todos los individuos presentan un buen estado general de salud. La prevalencia moderada de caries en los esqueletos más antiguos sugiere una ingesta con importante contenido de carbohidratos, lo que podría indicar que la importancia de los vegetales cariogénicos en la dieta ya era significativa en el Holoceno tardío inicial (Prates et al. 2010a, en este volumen).

En segundo lugar, cabe mencionar y discutir la presencia de los dos esqueletos de cánidos y el posible entierro intencional de uno de ellos. Aunque no puede descartarse totalmente que estos restos hayan ingresado al contexto por la ocurrencia de un proceso natural, varios indicadores sugieren el origen antrópico de su integración al depósito arqueológico. En este sentido, el registro de elementos articulados en el esqueleto de $D$. avus sugiere que estaba entero y que, posiblemente, su desarticulación y dispersión se produjeron como resultado de las actividades agropecuarias que dispersaron y expusieron el resto de los cuerpos. Generalmente, este tipo de registro (esqueleto articulado) se forma cuando el animal muere dentro de su madriguera, lo que no sería aplicable a este caso porque los cánidos no construyen madrigueras en sedimentos sueltos. Considerando lo expuesto, la presencia de 
varios entierros humanos en el mismo médano y la ausencia total de meteorización en los huesos, la hipótesis del entierro intencional es la que mejor explica su registro en LM.

A diferencia de otras especies de mamíferos, los carnívoros han tenido una marcada connotación simbólica en la vida los cazadores-recolectores del sur de América del Sur. Fueron recurrentemente incluidos en prácticas mortuorias y adquirieron un status singular en el mundo de las creencias y los rituales (Bonomo 2006). Sin embargo, aun cuando era frecuente la incorporación de elementos dentales y craneales como parte de las ofrendas funerarias de los entierros humanos (Politis 2000; Prevosti et al. 2004), no se conocen ejemplos de sepultura de cánidos silvestres. La práctica de enterrar animales quedó casi exclusivamente restringida a ciertas especies domésticas, sobre todo perros (Prates et al. 2010b y c). Cabe preguntarse entonces cuáles fueron los motivos que llevaron a los ocupantes de LM a incorporar un zorro en un contexto mortuorio, de un modo aparentemente vedado a formas no domésticas. Una vía posible de explicación al tratamiento excepcional de este animal es que, como fue observado y discutido en casos etnográficos de cazadores-recolectores amazónicos, haya sido mantenido en cautiverio, amansado y mascotizado -tamed- (Descola 2002; Politis 2004). De acuerdo con este patrón de racionalidad, una vez que los animales -generalmente crías- entran en la esfera doméstica y pasan a integrar el entramado social del grupo, salen de la esfera de "lo animal" y adquieren un status semejante al de los humanos (Politis 2004). En la mayoría de los casos, incluso, luego de la muerte reciben un tratamiento semejante al de las personas.

En este caso de estudio, varias evidencias sugieren que se trata de un ejemplo de entierro individual de una mascota y no de un acompañamiento $\mathrm{u}$ ofrenda del entierro 3. En primer lugar, porque los intervalos de los fechados radiocarbónicos de ambos esqueletos no se solapan, sino que están separados por 157 años, lo que indica que no fueron contemporáneos. En segundo lugar, la presencia de elementos articulados en ambos esqueletos muestra que se mantuvieron parcialmente in situ y, por lo tanto, la distancia de ca. dos metros entre ellos es demasiado grande para atribuir ambos cuerpos al mismo entierro. Por último, el estadio juvenil de desarrollo del $D$. auus es congruente con lo esperado en el entierro de mascotas silvestres, dado que éstas generalmente mueren antes de la adultez.

\section{Actividades domésticas efectuadas en el sitio}

Manufactura y uso de los artefactos líticos

En cuanto a la producción de instrumentos líticos, las materias primas fueron obtenidas casi exclusivamente del ámbito local: de los depósitos de rodados fluviales y de las areniscas de la formación Río Negro. Las únicas rocas de procedencia no local son cuarcitas que podrían provenir de los sistemas serranos de Ventania y Tandilia -en la provincia de Buenos Aires-, distantes ca. 220 y 540 km, respectivamente.

Con respecto a las materias primas modificadas mediante talla, el empleo de rocas locales se refleja en el patrón de reducción de los núcleos, caracterizado por escasas extracciones efectuadas a cada rodado y por su poca estandarización morfológica. Llama la atención, sin embargo, la ausencia de núcleos de rocas silíceas, que constituyen la principal materia prima utilizada en el sitio. Probablemente, este sesgo en el registro sea el resultado de un aprovechamiento más intensivo y de la consecuente pérdida de visibilidad arqueológica de los núcleos agotados (Prates 2008). La mayor parte de los instrumentos de filo manufacturados por talla presenta escasas modificaciones, en su mayoría retoque ultramarginal unifacial. La confección de este tipo de artefactos coincide con lo esperado en un contexto de disponibilidad local de diversas materias primas de buena calidad (Andrefsky 1998). Posiblemente, estos artefactos con escasas modificaciones fueron producidos, utilizados y descartados en el mismo lugar luego de realizarse la actividad para la que fueron concebidos (Binford 1979; Bamforth 1986). Los raspadores, que constituyen el grupo tipológico más abundante, se caracterizan por una baja estandarización morfológica y por sus pequeñas dimensiones -no superan por lo general los $3 \mathrm{~cm}$ de largo-. Los instrumentos que reflejan un mayor tiempo relativo de trabajo invertido en su manufactura son las puntas de proyectil que, como fue señalado, presentan una gran diversidad morfológica. Esta diversidad es mayor a la registrada en sitios prehispánicos del Holoceno tardío final de Norpatagonia, en los que predominan generalmente 
las formas triangulares apedunculadas de tamaño pequeño asociadas con el uso del arco de flechas (Prates 2007a). La presencia de algunas puntas de tamaño mediano podría indicar el empleo de otro tipo de propulsión para los proyectiles (Aschero y Martínez 2001).

El sitio LM registra una alta abundancia relativa de instrumentos modificados por uso y manufacturados mediante técnicas diferentes a la talla (picado, abrasión y pulido). Entre los aspectos más destacables de los instrumentos no tallados, principalmente los de molienda, debe mencionarse el bajo grado de formatización y estandarización morfológica y el alto índice de fracturación de las piezas $(73,7 \% ; n=28)$. La ausencia de instrumentos formales ha sido observada en la mayor parte de los sitios del área de estudio (Prates 2007b) y, como el caso de los artefactos tallados, podría ser el resultado de la aplicación de una estrategia expeditiva (sensu Nelson 1991) en el uso de las materias primas locales. Aunque no se hará aquí referencia pormenorizada acerca de los posibles usos de los artefactos no tallados, muy probablemente fueron empleados para la confección de otros instrumentos líticos (percutores) $y$, sobre todo, para el procesamiento de materiales blandos (minerales, vegetales, cuero y/o carne). Los restos de pigmento rojo son las únicas evidencias de materiales blandos identificadas mediante el análisis macroscópico de cuatro artefactos: un mortero, un artefacto pasivo simple, un rodado y un hacha. Es posible que los dos primeros hayan sido empleados para la preparación del colorante mediante la reducción a polvo o la formatización del pigmento (véanse otros casos en Matarrese et al. 2010). En el caso de un rodado sin formatización -posiblemente un pulidor-, el uso habría estado vinculado con la aplicación del colorante sobre otra superficie (por ej. cerámica o cuero). Y, en el caso del hacha, el colorante habría constituido una aplicación ornamental sobre el instrumento.

Procesamiento y consumo de fauna

En cuanto al registro arqueofaunístico de LM, en este artículo se pondrá énfasis en dos aspectos principales: el procesamiento y consumo de especies y el hábitat de las especies aprovechadas y sus implicancias en el uso de los distintos sectores del paisaje por los cazadores-recolectores. En cuanto al primero de los puntos, y sobre la base del análisis de los restos faunísticos, se propone que al menos una parte de las especies fue introducida en el sitio por la actividad humana. Algunas de ellas, como el guanaco y el venado, presentan evidencias directas de explotación humana. En el caso del guanaco, el 50\% de los huesos presenta marcas de utilización y el 36\% fracturas frescas realizadas probablemente con la finalidad de extraer médula ósea. Si bien estas especies no fueron las únicas explotadas, habrían provisto el mayor volumen de carne, si se tienen en cuenta sus altos valores de biomasa. Si se considera la representación de partes esqueletarias del cráneo y post-cráneo, al menos uno de los guanacos (NMI=2) y los dos venados registrados en la muestra habrían sido ingresados enteros en el sitio. En el caso de los peces y los moluscos, aun cuando no presentan evidencias directas de explotación, varios datos del contexto sugieren que también fueron acumulados por los seres humanos. En el primer caso, dado que los peces fueron recuperados sobre sedimentos de origen eólico, necesariamente debe recurrirse a la participación de algún agente de transporte para explicar su acumulación. El agente humano surge como más probable debido a que la frecuencia de elementos quemados $(62,5 \%)$ es significativamente superior a la de otros taxones presentes en el sitio $y$, por lo tanto, no puede explicarse tal diferencia por la acción de fuego natural. En el caso de los moluscos, la presencia de especímenes quemados, su ubicación en un sustrato eólico topográficamente alejado del ambiente natural de depositación y la inexistencia de otros potenciales agentes acumuladores, también sugieren la participación humana en su incorporación al contexto (véase discusión en Prates y Marsans 2007). Asimismo, las valvas de moluscos marinos fueron utilizadas probablemente como herramientas (contenedores) o materia prima para fabricar adornos (confección de discos perforados ornamentales).

En cuanto al hábitat de las especies aprovechadas y sus implicancias en el uso de los distintos sectores del paisaje por los cazadores-recolectores, debe señalarse en primer lugar, que pueden diferenciarse tres biotopos principales en las inmediaciones del sitio. Cada uno de estos biotopos, aunque se encuentran muy próximos entre sí, se caracterizan por un particular y diferente tipo de fauna. El prime- 
ro se ubica en los sectores más bajos de la cuenca vinculados con el río o con lagunas formadas en los paleocauces, el segundo representa todo el sector del valle sin vinculación espacial directa con lagunas o cauces del río, y el tercero se encuentra en las mesetas y planicies ubicadas fuera de la cuenca. En este sentido, entre la fauna explotada en el sitio se encuentran representadas especies propias de los tres biotopos. Los peces y moluscos se obtuvieron en el primer biotopo, los venados -que sólo habitan áreas abiertas con disponibilidad de pastos verdes (Merino 2003) y, posiblemente también los huevos de ñandú en el segundo, y los guanacos en el tercero. Es decir, los grupos establecidos en el sitio aprovecharon toda la diversidad de microambientes disponibles en el entorno (ambiente fluvial/lagunar, áreas abiertas del valle y mesetas altas).

\section{Uso de recipientes de cerámica}

En relación con la tecnología cerámica, la única técnica inferida de levantado de las piezas es la de superposición de rodetes, que pudo reconocerse claramente en el Conjunto 2. En cuanto al proceso de quema, las diferencias cromáticas observadas entre los márgenes y el núcleo (más marcadas en el sector del cuerpo inferior del cuenco) pueden relacionarse con la posición de la vasija respecto de la fuente de calor (por ejemplo vasijas colocadas boca abajo) y/o con la falta de una cocción larga y estable necesaria para alcanzar un equilibrio homogéneo en toda la vasija (García Roselló y Calvo Trias 2006). Los núcleos de color gris oscuro pueden explicarse por: a) presencia de materia orgánica en la pasta; b) cocción en una atmósfera que no fue lo suficientemente oxidante y c) cocción a una temperatura que no fue lo suficientemente alta para borrar el núcleo aun bajo atmósfera oxidante (López 1999/2001). Estas características han sido vinculadas generalmente con cocciones a cielo abierto con bajas temperaturas, comunes entre grupos cazadores-recolectores (véase discusión en García Roselló y Calvo Trias 2006). No se reconocieron en el conjunto indicadores primarios de manufactura de vasijas in situ (por ej. masas de arcillas semi-cocidas y fogones con restos cerámicos asociados).

En cuanto a los tratamientos de superficie, se destaca la presencia de tiestos con incisiones e impresiones. Aunque son muy escasos los estudios específicos de cerámica en Norpatagonia ${ }^{2}$ como para inferir asociaciones extra-regionales, la decoración cercana al borde (líneas rectas horizontales, zigzags, triángulos, reticulados o enrejados y rayas rítmicas verticales) también fue observada en otros sitios del río Negro, del golfo de San Matías y de la península de San Blas (véase Torres 1922; Bellelli 1980; Eugenio y Aldazabal 2004; entre otros).

Respecto del uso de la cerámica, las evidencias (directas e indirectas) más concluyentes fueron observadas en el cuenco parcialmente reconstruido (Conjunto 2) y sugieren que fue utilizada para la cocción. El hollín es un subproducto de la combustión y su presencia sobre los lados de la vasija confirma que el contenedor fue apoyado directamente sobre el fuego (Hally 1983). Por otro lado, de acuerdo con estudios experimentales y etnoarqueológicos, varios atributos morfológicos son consistentes con esta hipótesis: a) el diámetro estimado de la boca es de aproximadamente $320 \mathrm{~mm}$ y coincide con el diámetro máximo del contenedor, lo que le otorga buena accesibilidad a su interior (Rice 1987:225); b) el contorno simple sin inflexiones evita el calentamiento desparejo y el stress térmico durante la exposición al fuego que se producen en las vasijas con ángulos agudos y c) las paredes relativamente finas conducen mejor el calor e incrementan la resistencia al shock térmico (Rice 1987).

Por último, numerosos autores proponen que entre grupos cazadores asentados en ambientes acuáticos (a lo largo de la costa marina, en valles fluviales, entre otros) la tecnología cerámica ha permitido la explotación más eficiente de peces, mamíferos acuáticos y moluscos (véase discusión en Rice 1999 y Jordan y Zvelebil 2009). Si bien esta hipótesis parece haber sido corroborada, por ejemplo, en la Depresión del río Salado mediante el estudio de ácidos grasos (González 2005), en LM es necesario efectuar este tipo de análisis para confirmar el procesamiento de la fauna fluvial.

\section{CONSIDERACIONES FINALES}

Sobre la base del análisis integral de los materiales, LM fue interpretado como un sitio de actividades múltiples con entierros humanos esta-

2 En esta región los fechados confiables más antiguos de alfarería se ubican ca. 1.500 años AP (Eugenio y Aldazabal 2004). 
blecido en una geoforma eólica (médano). Los cinco fechados radiocarbónicos obtenidos indican que fue ocupado en forma discontinua durante por lo menos 2.500 años. En el sitio se realizaron prácticas mortuorias, que incluyen el entierro de un número mínimo de cinco cuerpos humanos y un cánido extinto, durante un período comprendido entre ca. 2000 y 3000 años AP. Además de haber funcionado como un espacio para enterrar a los muertos, el registro analizado indica que el mismo médano fue utilizado como área de actividades múltiples, al menos una vez, hacia los 500 años AP.

Todos los entierros humanos registrados en el sitio son primarios; incluyen individuos adultos, subadultos, femeninos y masculinos y ninguno presenta acompañamiento funerario. A pesar de sus diferencias cronológicas, no se registraron entre ellos diferencias sustanciales en cuanto al estado de salud general. Uno de los esqueletos de cánido hallados cerca del entierro 3 habría sido enterrado, posiblemente por tratarse de un animal silvestre incorporado como mascota a la vida del grupo.

El estudio de los materiales del sitio muestra un fuerte énfasis en la explotación de los recursos de los distintos sectores del valle (sectores fluviales bajos y áreas abiertas alejadas del río) y, en menor medida, de las mesetas altas adyacentes. Los artefactos líticos, como ocurre en la mayor parte de los sitios de la cuenca del río Negro (Prates 2008), fueron confeccionados casi exclusivamente sobre rocas locales (rodados y areniscas del río Negro). Salvo las puntas de proyectil, los instrumentos son poco estandandarizados y es posible que en su mayoría se hayan confeccionado en el lugar y descartado luego del abandono del sitio. Además del guanaco, venado, dasipódidos, ñandú y moluscos, es posible que se hayan explotado algunos vegetales debido a la abundancia y diversidad de instrumentos de molienda. La presencia de las dos especies de rheidos en el registro arqueofaunístico permite plantear que las condiciones ambientales hace 500 años habrían sido similares a las actuales, si se considera la especificidad climática necesaria para su coexistencia. El análisis de la alfarería del sitio muestra que fue utilizada para la cocción, aunque todavía no se tiene información del tipo de alimentos procesados. Las características generales de la decoración de las vasijas de LM sugieren mayores semejanzas con los registros del litoral marítimo que con los de la ribera norte del río. Sin embargo, es necesario considerar las variantes contextuales y profundizar en los análisis morfológicos y funcionales para interpretar la variabilidad de la cerámica identificada en ambas márgenes del río.

Para finalizar, deben mencionarse algunas implicancias derivadas de la asociación espacial estricta entre el médano y el área de dispersión de los materiales arqueológicos. Teniendo en cuenta que los médanos son rasgos del paisaje que han sido recurrentemente utilizados para el asentamiento en la mayor parte del mundo (Wandsnider 1988) y, particularmente, en Norpatagonia (Moreno 1874; Fisher y Nacuzzi 1992; Sanguinetti de Bórmida 1999; Martínez y Figuerero Torres 2000; Prates et al. 2006; Borella et al. 2007; entre otros), no puede interpretarse la repetida ocupación del sitio sin considerar la atracción que generaba este tipo de geoforma para los grupos cazadores-recolectores. La presencia de un área residencial y numerosos entierros diacrónicos en el mismo sector del paisaje no implicaría en este caso la existencia de un espacio sacralizado, especialmente destinado a las sepulturas, sino el resultado de la recurrente selección del lugar por sus rasgos favorables (espaciales, sedimentarios y topográficos) para el asentamiento y las prácticas mortuorias (véase Schelanger 1992). Si así fuera, el concepto de "cementerio" y sus connotaciones de territorialidad (Littleton y Allen 2007) no serían apropiados para explicar el sitio LM ni, probablemente, muchos otros similares de la misma cuenca y del litoral marítimo. Además de la disponibilidad de recursos cerca del sitio y el dominio visual logrado desde el médano (Prates et al. 2010a, en este volumen), deben considerarse también como posibles determinantes de la persistencia en la ocupación, la confortabilidad que ofrece el sustrato arenoso para el asentamiento y para la excavación de las fosas para las sepulturas. Los médanos parecen haber constituido una de las principales y más significativas geoformas donde habitaron los cazadores-recolectores de la cuenca inferior del río Negro, en particular, y del este de Norpatagonia, en general.

\section{AGRADECIMIENTOS}

Deseamos expresar nuestro agradecimiento a Gustavo Martínez, María Isabel González, Gustavo Politis e Irene del Llano por la lectura crítica del 
manuscrito y por sus valiosos aportes. A Francisco Prevosti por la determinación de los restos de cánido y a Diego Gobbo por su asistencia durante la preparación de las figuras. A Marcelo Martínez y familia por su excelente predisposición para que podamos trabajar dentro de su propiedad y a Walter Bini por su constante colaboración y cordialidad durante los trabajos de campo. Los recursos para la ejecución de esta investigación fueron obtenidos de la ANPCyT (PICT N²64-2006 y PICT $\mathrm{N}^{\circ}$ 01588-2007).

\section{BIBLIOGRAFIA}

ANDREFSKY, W. 1998. Lithics macroscopic approaches to analysis. Cambridge University Press, Cambridge.

ANDREIS, R. A. 1965. Petrografía y paleocorrientes de la formación Río Negro. Revista del Museo de La Plata (N.S.) 36 (5): 245-310.

APOLINAIRE, E. y L. TURNES. 2008. Diferenciación específica de rheidos a partir de fragmentos de cáscaras de huevo. Su contrastación en cuatro sitios arqueológicos del Holoceno tardío. En: Libro de resúmenes del $\mathrm{V}$ Congreso de la Región Pampeana Argentina. Santa Rosa, La Pampa.

ASCHERO, C. 1983. Registro de códigos para atributos descriptivos aplicados a artefactos líticos. Informe el CONICET, MS. Departamento Científico de Arqueología, Facultad de Ciencias Naturales y Museo, Universidad Nacional de La Plata, La Plata.

ASCHERO, C. y S. HOCSMAN. 2004. Revisando cuestiones tipológicas en torno a la clasificación de artefactos bifaciales. En: Temas de Arqueología. Análisis Lítico, compilador por M. Ramos, A. Acosta y D. Loponte, pp. 7-25. Universidad Nacional de Luján, Luján.

ASCHERO, C. y J. MARTÍNEZ. 2001. Técnicas de caza en Antofagasta de la Sierra, Puna Meridional Argentina. Relaciones de la Sociedad Argentina de Antropología 26: 215-241.

BABOT, M. P. 2004. Tecnología y utilización de artefactos de molienda en el Noroeste prehispánico. Tesis Doctoral no publicada, Facultad de Ciencias Naturales e I.M.L, Universidad Nacional de Tucumán.

BALFET, H., M. F. FAUVET-BERTHELOT y S. MONZÓN. 1992. Normas para la descripción de vasijas cerámicas. México, Centre D’Études Mexicaines et Centroaméricaines (CEMCA).

BAMFORTH, D. 1986. Technological efficiency and tool curation. American Antiquity 51 (1): 38-50.
BEHRENSMEYER, A. K. 1978. Taphonomic and ecologic information from bone weathering. Paleobiology 4 (2): 150-162.

BELLELLI, C. 1980. La decoración de la cerámica gris incisa de Patagonia (República Argentina). Revista do Museu Paulista 27: 199- 225.

BERNAL, V., P.N. GONZÁLEZ, S.I. PEREZ y H. PUCCIARELLI. 2008. Entierros humanos del nordeste de Patagonia: Nuevos fechados radiocarbónicos. Magallania 36 (2): 125-134.

BINFORD, L. R. 1979. Organization and formation processes: looking at curated technologies. Journal of Anthropological Research 35 (3): 225-273.

BONOMO, M. 2006. Un acercamiento a la dimensión simbólica de la cultura material en la región pampeana. Relaciones de la Sociedad Argentina de Antropología 31: 89-115.

BORELLA F., C. MARIANO y C. M. FAVIER DUBOIS. 2007. Procesos tafonómicos en restos humanos de la localidad arqueológica de Bajo de la Quinta, Golfo San Matías (Río Negro), Argentina. En: Arqueología de Fuego-Patagonia. Levantando piedras, desenterrando huesos...y develando arcanos, editado por F. Morello, M. Martinic, A. Prieto y G. Bahamonde, pp. 403-410. Ediciones Cequa, Punta Arenas.

DESCOLA, P. 2002. La antropología y la cuestión de la naturaleza. En: Repensando la naturaleza. Encuentros y desencuentros disciplinarios en torno a lo ambiental, editado por Palacio, Germán y Ulloa, Astrid, pp. 155171. UN-Imani-ICAHN, Bogotá.

DINCAUZE, D. 2000. Enviromental Archaeological Principles and Practice. Cambridge University Press, Cambridge.

EUGENIO, E. y V. ALDAZABAL. 2004. Los cazadoresrecolectores del litoral marítimo del área de bahía San Blas, provincia de Buenos Aires. En: Contra viento y marea. Arqueología de Patagonia, editado por M. T. Civalero, P. M. Fernández y A. G. Guráieb, pp. 687-700. INAPL-SAA, Buenos Aires.

FISHER, A. y L. R. NACUZZI. 1992. La destrucción sistemática del paisaje y de los sitios arqueológicos. El caso del Valle de Viedma. Arqueología 2: 189-229.

GARCÍA ROSSELLÓ, J. y M. CALVO TRIAS. 2006. Análisis de las evidencias macroscópicas de cocción en la cerámica prehistórica: una propuesta para su estudio. Mayurqa 31:83-112.

GONZÁLEZ, M. I. 2005. Arqueología de alfareros, cazadores y pescadores pampeanos. Colección tesis doctorales, Sociedad Argentina de Antropología, Buenos Aires.

HALLY, D. J. 1983. Use alteration of pottery vessel surfaces: An important source of evidence in the identification of vessel function. North American Archaeologist 4(1): 3-26. 
JORDAN, P. y M. ZVELEBIL. 2009. Ex Oriente Lux: the prehistory of hunter gatherer ceramic dispersals. En: Ceramics Before Farming: The Dispersal of Pottery Among Prehistoric Eurasian Hunter-Gatherers, editado por P. Jordan y M. Zvelebil, pp.3-88. University College London Institute of Archaeology Publications, Left Coast Press.

LEHMANN-NITSCHE, R. 1930. Un cráneo patagón con pinturas geométricas en rojo y negro procedente de San Blas (costa atlántica). Revista del Museo de la Plata 32: 239-280.

LITTLETON, J., y H. ALLEN. 2007. Hunter-gatherer burials and the creation of persistent places in southeastern Australia. Journal of Anthropological Archaeology 26: 283-298.

LÓPEZ, M. A. 1999/2001. Los núcleos de cocción en las pastas cerámicas arqueológicas, indicadores y variables relacionados con algunos aspectos de la secuencia de producción. Xama 12-14: 133-149.

LUCHSINGER, H. 2006. The late Quaternary landscape history of the middle río Negro valley, Northern Patagonia, Argentina: Its impact on preservation of the archaeological record and influence on Late Holocene human settlement patterns. Dissertation (PhD) no publicada. A\&M Texas University.

LUCHSINGER, H. y L. PRATES. 2009. Human Occupation of Abandoned River Channels in the Middle Río Negro Valley, Northern Patagonia, Argentina. MS.

LYMAN, R. 1994. Vertebrate Taphonomy. Cambridge Manuals in Archaeology. Cambridge University Press, Cambridge.

MARTínEZ, G. y M. J. FIGUERERO TORRES. 2000. Sitio arqueológico La Petrona (Partido de Villarino, Provincia de Buenos Aires). Relaciones de la Sociedad Argentina de Antropología 25: 227-247.

MARTÍNEZ, G., P. BAYALA, G. FLENSBORG y R. LÓPEZ. 2006. Análisis preliminar de los entierros humanos del sitio Paso Alsina 1 (Pcia. de Buenos Aires). Intersecciones en Antropología 7: 95-108.

MATARRESE, A., V. DI PRADO y D. POIRÉ. 2010. Petrologic analysis on mineral pigments from hunter-gatherers archaeological contexts (southeast of Pampean region, Argentina). Trabajo enviado para su publicación en Quaternary International.

MERINO, M. L. 2003. Dieta y uso de hábitat del venado de las pampas, Ozotoceros bezoarticus celer Cabrera 1943 [Mammalia - Cervidae] en la zona costera de Bahía Samborombón, Buenos Aires, Argentina. Implicancias para su conservación. Tesis doctoral no publicada. Facultad de Ciencias Naturales y Museo, Universidad Nacional de La Plata.
MIOTTI, L. 1998. Zooarqueología de la meseta central y costa de Santa Cruz. Un enfoque de las estrategias adaptativas aborígenes y los paleoambientes. Museo Municipal de Historia Natural, San Rafael.

MORENO, F. P. 1874. Description des cimetières et paraderos prehistoriques de Patagonie. Revue d'Antropologie 3: 72-90.

NELSON, M. 1991. The study of technological organization. Archaeological Method and Theory, editado por M. B. Schiffer, vol. 3, pp. 57-100. University of Arizona Press, Tucson.

ORTON, C., P. TYERS y A. VINCE. 1997. La Cerámica en Arqueología. Crítica, Barcelona.

PALEO, C. y M. PÉREZ MERONI. 2005-2006. Dimensión social de la tecnología cerámica en sociedades cazadoras-recolectoras. Revista do Museu de Arqueologia e Etnologia, São Paulo, 15-16: 73-85.

POLITIS, G. G. 2000. Patrones de descarte de los nukak: implicaciones para la arqueología de los cazadores-recolectores. Arqueología del Área Intermedia 2: 99-124.

POLITIS, G. G. 2004. La domesticación de plantas y animales en las tierras bajas tropicales. Conferencia dictada en el XV Congreso Nacional de Arqueología Argentina. Río Cuarto, Córdoba.

PRATES, L. 2007A. Tecnología y diseño de los artefactos líticos en el valle medio del río Negro y su relación con otros sectores de Norpatagonia. Trabajo presentado en XVI Congreso Nacional de Arqueología Argentina. San Salvador de Jujuy, Jujuy.

PRATES, L. 2007B. Arqueología del valle medio del río Negro (provincia de Río Negro). Tesis Doctoral no publicada. Facultad de Ciencias Naturales y Museo. Universidad Nacional de La Plata.

PRATES, L. 2008. Los indígenas del río Negro. Un enfoque arqueológico. Colección Tesis doctorales de la Sociedad Argentina de Antropología.

PRATES, L., G. MARTÍNEZ y C. SCABUZZO. 2006. Evidencias arqueológicas del Holoceno tardío final en el curso medio del río Colorado (provincia de Río Negro): sitio Don Aldo 1. Cazadores-recolectores del Cono Sur 1: 163-177.

PRATES, L. y N. MARSANS. 2007. El uso de moluscos de agua dulce (Diplodon chilensis patagonicus) en el sitio Angostura 1 (Departamento de General Conesa, Río Negro). Intersecciones en Antropología 8:355-359.

PRATES, L., G. A. FLENSBORG y P. BAYALA. 2010a. Caracterización de los entierros humanos del sitio Loma de los Muertos (valle medio del río Negro, Argentina). Magallania. 38(1): 147-162. 
PRATES, L., F. J. PREVOSTI y M. BERÓN. 2010b. First Records of Prehispanic Dogs in Southern South America (Pampa-Patagonia, Argentina) Current Anthropology 51(2): 273-280.

PRATES, L., M. BERÓN y F. J. PREVOSTI. 2010c. Los perros prehispánicos del Cono Sur. Tendencias y nuevos registros. Mamül Mapu: pasado y presente desde la arqueología pampeana, editado por M. Berón, L. Luna, M. Bonomo, C. Montalvo, C. Aranda y M. Carrera Aizpitarte, pp. 129-142. Editorial Libros del Espinillo, Buenos Aires.

PREVOSTI, F. J., M. BONOMO y E. P. TONNI. 2004. La distribución de Chrysocyon brachyurus (Illiger, 1811]) (Mammalia: Carnivora: Canidae) durante el Holoceno en la Argentina: implicancias paleoambientales. Mastozoología Neotropical Mammal 11(1): 27-43.

RICE, P. M. 1987. Pottery analyisis: A sourcebook. University of Chicago Press, Chicago.

RICE, P. M. 1999. On the Origins of Pottery. Journal of Archaeological Method and Theory 6(1): 1-54.

SANGUINETTI DE BÓRMIDA, A. C. 1999. Proyecto Norpatagonia. Arqueología de la Costa Septentrional. Separata de Anales de la Academia Nacional de Ciencias de Buenos Aires, Buenos Aires.
SCHELANGER, S., 1992. Recognizing persistent places in Anasazi setlement systems. En: Space, time and Archaeological Landscapes, editado por J. Rossignol y L. Wandsnider, pp. 91-112. Plenum Press, New York.

SKIBO, J. M. 1992. Pottery function. A use-alteration perspective. Plenum Press, New York.

TORBEN, R. 2002. Eolian Processes, Ground Cover, and the Archaeology of Coastal Dunes: A Taphonomic Case Study from San Miguel Island, California, U.S.A. Geoarchaeology 17: 811-833.

TORRES, L. M. 1922. Arqueología de la península de San Blas (provincia de Buenos Aires). Notas preliminares del Museo La Plata 26, tercera serie, tomo II: 473-532.

VIGNATI, M. A. 1938. Cráneos pintados del cementerio indígena de San Blas. Revista del Museo de La Plata (N.S) 1: 35-52.

WANDSNIDER, L. 1988. Experimental investigation of the effect of dune processes on archaeological remains. American Antiquity 7 (1): 18-28.

WATERS, M. R. 1992. Principles of geoarchaeology: a North American perspective. The University of Arizona Press, Tucson. 
